\title{
A Checklist of Metazoan Parasites from Rainbow Trout (Oncorhynchus mykiss)
}

\author{
By K. Buchmann, A. Uldal and H. C. K. Lyholt
}

Department of Veterinary Microbiology, Section of Fish Diseases, The Royal Veterinary and Agricultural University, Frederiksberg, Denmark.

\begin{abstract}
Buchmann, K., A. Uldal and H. Lyholt: A checklist of metazoan parasites from rainbow trout Oncorhynchus mykiss. Acta vet. scand. 1995, 36, 299-318. - An extensive literature survey on metazoan parasites from rainbow trout Oncorhynchus mykiss has been conducted. The taxa Monogenea, Cestoda, Digenea, Nematoda, Acanthocephala, Crustacea and Hirudinea are covered. A total of 169 taxonomic entities are recorded in rainbow trout worldwide although few of these may prove synonyms in future analyses of the parasite specimens. These records include Monogenea (15), Cestoda (27), Digenea (37), Nematoda (39), Acanthocephala (23), Crustacea (17), Mollusca (6) and Hirudinea (5). The large number of parasites in this salmonid reflects its cosmopolitan distribution.
\end{abstract}

helminths; Monogenea; Digenea; Cestoda; Acanthocephala; Nematoda; Hirudinea; Crustacea; Mollusca.

\section{Introduction}

The importance of the rainbow trout Oncorhynchus mykiss (Walbaum) in aquacultural enterprises has increased significantly during the last century. The annual total world production of this species has been estimated to 271,478 metric tonnes in 1990 exceeding that of Salmo salar (FAO 1991). In the year 1993 the Danish annual production of rainbow trout in freshwater culture systems reached 35,000 tonnes and in mariculture 6,600 tonnes. To optimize the Danish production a research programme on rainbow trout biology was implemented in 1993. As a part of this study parasite infections are monitored in selected farms and a literature survey on world records of metazoan parasites in rainbow trout has been conducted to establish data for comparison. The protozoan parasites from the rainbow trout was previously listed by Lom \& $D y$ - kova (1992) and the present paper lists the recorded metazoan parasites from this host. In order to prevent a reference list being too extensive, priority has been given to reports compiling data for the appropriate geographical regions or early records in a particular area. Thus, a number of excellent papers on these parasites have been omitted only because the treated parasite species and their geographical distribution have already been presented by other authors in the list. Where possible, the classification of the Acanthocephala is in accordance with Amin (1985), who revised the taxonomy of fish acanthocephalans. In addition the recommendations on nematode taxonomy in Moravec (1971) and De \& Moravec (1979) have been followed. Recent studies on cestode taxonomy conducted by Hanzelova \& Scholz (1993) and Scholz \& Hanzelova (1994) are also consid- 
ered. Oncorhynchus mykiss is considered a synonym for Salmo gairdneri, Salmo irideus and Salmo mykiss in accordance with Kendall (1988) and Smith \& Stearly (1989).

The geographic regions are of practical rea- sons conservative. Thus the former USSR territory is still designated USSR, the area of the former Yugoslavian republic is still called Yugoslavia and the area of the Czech and the Slovak republics are named CS.

Table 1. List of metazoan parasites from rainbow trout.

\begin{tabular}{|c|c|}
\hline Species name & Country/region, and author (year) \\
\hline \multicolumn{2}{|l|}{ Monogenea } \\
\hline $\begin{array}{l}\text { Discocotyle sagittata (Leuckart } 1842 \text {, } \\
\text { Diesing 1850) }\end{array}$ & $\begin{array}{l}\text { UK (Kennedy 1974, Kennedy et al. 1991), } \\
\text { Canada (Margolis \& Arthur 1979). }\end{array}$ \\
\hline Discocotyle salmonis (Schaffer 1916) & North America (Hoffman 1967). \\
\hline Gyrodactylus sp. & $\begin{array}{l}\text { UK (Poynton and Bennett 1985, } \\
\text { McGuigan \& Sommerville 1985), } \\
\text { Canada (Hare \& Frantsi 1974, Margolis \& Arthur 1979), } \\
\text { Germany (Rosengarten 1985), } \\
\text { North America (Hoffman 1967, Muzzall 1993). }\end{array}$ \\
\hline Gyrodactylus truttae (Gläser 1974) & $\begin{array}{l}\text { USSR (Gussev 1985), } \\
\text { Bulgaria (Kakacheva-Avramova \& Menkova 1979, 1982), } \\
\text { Germany (Lux 1991). }\end{array}$ \\
\hline $\begin{array}{l}\text { Gyrodactylus derjavini (Mikailov 1975) } \\
\text { (sensu Malmberg \& Malmberg 1987) }\end{array}$ & $\begin{array}{l}\text { Denmark (Malmberg 1989, 1993, Buchmann et al. 1985), } \\
\text { Sweden (Malmberg 1973, 1989, 1993) } \\
\quad \text { Malmberg \& Malmberg 1991), } \\
\text { Poland (Prost 1991). }\end{array}$ \\
\hline Gyrodactylus salmonis (Yin \& Sproston 1948) & $\begin{array}{l}\text { Canada (Cone et al. 1983, Wells \& Cone 1990, } \\
\text { Cone \& Cusack 1988), } \\
\text { USA (Cone et al. 1983). }\end{array}$ \\
\hline Gyrodactylus lavareti (Malmberg 1957) & Finland, Sweden (Malmberg 1993). \\
\hline Gyrodactylus gobii (Schulman 1953) & Germany (Lux 1991). \\
\hline Gyrodactylus salaris (Malmberg 1957) & $\begin{array}{l}\text { Sweden (Malmberg 1989, 1993, } \\
\quad \text { Malmberg \& Malmberg 1991), } \\
\text { Finland (Malmberg 1989, 1993), } \\
\text { Denmark (Malmberg \& Malmberg 1987, 1991, 1993, } \\
\quad \text { Buchmann et al. 1995), } \\
\text { CS (Lucky 1963, Rehulka 1973), } \\
\text { Germany (Lux 1991), } \\
\text { Norway (Mo 1991, Bakke et al. 1991), } \\
\text { Yugoslavia (Zitnan \& Cankovic 1970), } \\
\text { Spain (Tojo et al. 1992). }\end{array}$ \\
\hline Gyrodactylus brevis (Crane et Mizelle 1967) & USA (Crane \& Mizelle 1967). \\
\hline $\begin{array}{l}\text { Gyrodactylus colemanensis } \\
\text { (Mizelle \& Kritsky 1967) }\end{array}$ & $\begin{array}{l}\text { USA (Mizelle \& Kritsky 1967, Cone et al. 1983), } \\
\text { Canada (Cone et al. 1983, Cusack 1986, } \\
\text { Cone \& Cusack 1988, Wells \& Cone 1990). }\end{array}$ \\
\hline
\end{tabular}


Table 1 - continued

\begin{tabular}{|c|c|}
\hline Species name & Country/region, and author (year) \\
\hline $\begin{array}{l}\text { Gyrodactylus avalonia } \\
\text { (Hanek \& Threllfall 1969) }\end{array}$ & Canada (Cone et al. 1983). \\
\hline Gyrodactylus bohemicus (Ergens 1992) & CS (Ergens 1992). \\
\hline Gyrodactylus masu (Ogawa 1986) & Japan (Ogawa 1986). \\
\hline Tetraonchus alascensis (Price 1937) & $\begin{array}{l}\text { USSR (Pavlovski 1964, Gussev 1985), } \\
\text { North America (Hoffman 1967). }\end{array}$ \\
\hline \multicolumn{2}{|l|}{ Digenea } \\
\hline Acrolichanus similis (Wisniewski 1933) & Yugoslavia (Wisniewski 1933). \\
\hline Allocreadium lobatum (Wallin 1909) & $\begin{array}{l}\text { Canada (Margolis \& Arthur 1979), } \\
\text { North America (Hoffman 1967). }\end{array}$ \\
\hline Aponorus sp. & North America (Hoffman 1967). \\
\hline $\begin{array}{l}\text { Apatemon gracilis (Rudolphi 1819) } \\
\text { Szidat } 1928 \text { (metacercaria) }\end{array}$ & UK (Blair 1976, McGuigan \& Sommerville 1985). \\
\hline Azygia lucii (Müller 1776) & Yugoslavia (Zitnan \& Cankovic 1970). \\
\hline $\begin{array}{l}\text { Bolbophorus confusus (Krause 1914) } \\
\text { (metacercaria) }\end{array}$ & North America (Hoffman 1967). \\
\hline Bunodera luciopercae (Müller 1776) & $\begin{array}{l}\text { UK (McGuigan \& Sommerville 1985,), } \\
\text { Canada (Mudry \& Anderson 1977, } \\
\text { Margolis \& Arthur 1979). }\end{array}$ \\
\hline Clinostomum sp. (metacercaria) & Canada (Margolis \& Arthur 1979). \\
\hline $\begin{array}{l}\text { Clinostomum marginatum (Rudolphi 1819) } \\
\text { (metacercaria) }\end{array}$ & North America (Hoffman 1967). \\
\hline Crepidostomum farionis (Müller 1780) & $\begin{array}{l}\text { USSR (Pavlovski 1964, Pugachev 1984), } \\
\text { Canada (Mudry \& Anderson 1977, } \\
\text { Margolis \& Arthur 1979), } \\
\text { North America (Hoffman 1967), } \\
\text { USA (Jones \& Hammond 1960, Mamer 1978, } \\
\text { Wier et al. 1983), } \\
\text { Yugoslavia (Wisniewski 1933), } \\
\text { UK (Kennedy et al. 1991). }\end{array}$ \\
\hline Crepidostomum cooperi (Hopkins 1931) & $\begin{array}{l}\text { USA (Muzzall 1993), } \\
\text { North America (Hoffman 1967). }\end{array}$ \\
\hline Crepidostomum metoecus (Braun 1900) & $\begin{array}{l}\text { UK (Kennedy et al. 1991), } \\
\text { Yugoslavia (Zitnan \& Cankovic 1970). }\end{array}$ \\
\hline Crepidostomum transmarinum (Nicoll 1909) & North America (Hoffman 1967). \\
\hline Deropegus aspina (McCauley et Pratt 1961) & North America (Hoffman 1967). \\
\hline Diplostomum sp. (metacercaria) & $\begin{array}{l}\text { UK (Kennedy 1974, McGuigan \& Sommerville 1985, } \\
\text { Kennedy et al. 1991), } \\
\text { Canada (Margolis \& Arthur 1979), } \\
\text { Germany (Reimer 1985), } \\
\text { Japan (Sato et al. 1976), } \\
\text { USA (Mamer 1978), }\end{array}$ \\
\hline
\end{tabular}


Table 1 - continued

\begin{tabular}{|c|c|}
\hline Species name & Country/region, and author (year) \\
\hline & $\begin{array}{l}\text { North America (Hoffman 1967), } \\
\text { Denmark (Buchmann \& Uldal 1994), } \\
\text { Poland (Reimer 1985). }\end{array}$ \\
\hline $\begin{array}{l}\text { Diplostomum spathaceum (Rudolphi 1819) } \\
\text { (metacercaria) }\end{array}$ & $\begin{array}{l}\text { UK (Rushton 1937, Betterton 1974, Kennedy 1974, } \\
\quad \text { Moody \& Gaten 1982), } \\
\text { Poland (Reimer 1985), } \\
\text { Finland (Tiainen 1966, Bylund \& Sumari 1981), } \\
\text { Germany (Fritzshe 1975), } \\
\text { USA (Palmieri et al. 1976), } \\
\text { Italy (Ghittino 1979), } \\
\text { USSR (Shigin 1972), } \\
\text { Sweden (Höglund 1991), } \\
\text { North America (Hoffman 1967), } \\
\text { Chile (Arata et al. 1977), } \\
\text { Denmark (Rasmussen \& Bregnballe 1962, } \\
\quad \text { Buchmann et al. 1995). }\end{array}$ \\
\hline $\begin{array}{l}\text { Diplostomum gasterostei (Williams 1966) } \\
\text { (metacercaria) }\end{array}$ & UK (McGuigan \& Sommerville 1985) \\
\hline $\begin{array}{l}\text { Diplostomum baeri bucculentum } \\
\text { (Dubois et Rausch 1948)(metacercaria) }\end{array}$ & Canada (Lei Ching 1985). \\
\hline Echinochasmus sp. (metacercaria) & $\begin{array}{l}\text { USA (Uzmann \& Hayduk 1964), } \\
\text { North America (Hoffman 1967). }\end{array}$ \\
\hline $\begin{array}{l}\text { Ichthyocotylurus erraticus (Rudolphi 1809) } \\
\text { Szidat 1928)(metacercaria) }\end{array}$ & $\begin{array}{l}\text { UK (Wootten 1973, Betterton 1974, Kennedy 1974), } \\
\text { Netherlands (Swennen et al. 1979). }\end{array}$ \\
\hline $\begin{array}{l}\text { Nanophyetus salmincola (Chapin 1926) } \\
\quad \text { (metacercaria) }\end{array}$ & $\begin{array}{l}\text { USA (Uzmann \& Hayduk 1964, Wilson \& Foreyt 1985), } \\
\text { North America (Hoffman 1967). }\end{array}$ \\
\hline Neascus sp. (metacercaria) & $\begin{array}{l}\text { Canada (Margolis \& Arthur 1979), } \\
\text { North America (Hoffman 1967). }\end{array}$ \\
\hline $\begin{array}{l}\text { Nicolla (= Coitocaecum) testiobliquum } \\
\quad \text { (Wisniewski 1932) }\end{array}$ & $\begin{array}{l}\text { Yugoslavia (Wisniewski 1933, Zitnan \& Cankovic 1970, } \\
\text { Kasic 1978). }\end{array}$ \\
\hline $\begin{array}{l}\text { Nicolla (= Coitocaecum) proavitum } \\
\quad \text { (Wisniewski 1933) }\end{array}$ & Yugoslavia (Wisniewski 1933). \\
\hline Phyllodistomum sp. & North America (Hoffman 1967). \\
\hline Phyllodistomum umblae (Fabricius) & Canada (Bakke \& Bailey 1987). \\
\hline Phyllodistomum lachancei (Choquette 1947) & North America (Hoffman 1967). \\
\hline $\begin{array}{l}\text { Plagioporus angusticole (Hausmann 1896) } \\
\text { Dobrovolny } 1939\end{array}$ & North America (Hoffman 1967). \\
\hline Podocotyle shawi (MacIntosh 1939) & North America (Hoffman 1967). \\
\hline Pseudechetosoma sp. & $\begin{array}{l}\text { Bulgaria (Kakacheva-Avramova \& Menkova 1982), } \\
\text { Yugoslavia (Bristol et al. 1984). }\end{array}$ \\
\hline Sanguinicola davisi (Wales 1958) & USA (Wales 1958, Rawstron 1971). \\
\hline Sanguinicola idahoensis (Schell 1974) & USA (Schell 1974). \\
\hline
\end{tabular}

(continued)

Acta vet. scand. vol. 36 no. 3 - 1995 
Table 1 - continued

\begin{tabular}{|c|c|}
\hline Species name & Country/region, and author (year) \\
\hline Sanguinicola sp. & North America (Hoffman 1967). \\
\hline Sphaerostomum globiporum (Rudolphi 1802) & Yugoslavia (Kazic 1978). \\
\hline Stephanostomum sp. (metacercaria) & Canada (McGladdery et al. 1988). \\
\hline $\begin{array}{l}\text { Tylodelphus podicipina (Kozicka } \\
\text { et Niewiadomska 1960)(metacercaria) }\end{array}$ & UK (Kennedy 1974). \\
\hline $\begin{array}{l}\text { Tylodelphus clavata (Nordmann 1832) } \\
\text { (metacercaria) }\end{array}$ & $\begin{array}{l}\text { UK (Betterton 1974, Kennedy 1974, Moody \& Gaten 1982, } \\
\text { McGuigan \& Sommerville 1985), } \\
\text { Denmark (Buchmann et al. 1995). }\end{array}$ \\
\hline \multicolumn{2}{|l|}{ Cestoda } \\
\hline Cyathocephalus truncatus (Pallas 1781) & $\begin{array}{l}\text { USSR (Pavlovskii 1964), } \\
\text { Yugoslavia (Wisniewski 1933, Zitnan \& Cankovic 1970), } \\
\text { Germany (Hermanns \& Körting 1986). }\end{array}$ \\
\hline Diphyllobothrium sp. (Plerocercoid) & $\begin{array}{l}\text { USSR (Konovalov } 1971 \text { cited by Pugachev 1984), } \\
\text { Canada (Mudry \& Anderson 1977, Margolis \& Arthur } \\
\text { 1979), } \\
\text { North America (Hoffman 1967), } \\
\text { USA (Mamer 1978, Muzzall 1993), } \\
\text { Argentina (Conroy, 1981). }\end{array}$ \\
\hline $\begin{array}{l}\text { Diphyllobothrium dendriticum } \\
\text { (Nitzsh 1824) (Plerocercoid) }\end{array}$ & $\begin{array}{l}\text { UK (Kennedy 1974, Kennedy et al. 1991), } \\
\text { Canada (Margolis \& Arthur 1979), } \\
\text { Norway (Halvorsen \& Wissler 1973, Andersen 1979), } \\
\text { Chile (Torres et al. 1989), } \\
\text { Argentina (Revenga 1993). }\end{array}$ \\
\hline $\begin{array}{l}\text { Diphyllobothrium ditremum (Creplin 1825) } \\
\text { (Plerocercoid) }\end{array}$ & $\begin{array}{l}\text { Canada (Margolis \& Arthur 1979), } \\
\text { Norway (Halvorsen \& Wissler 1973), } \\
\text { UK (Kennedy et al. 1991). }\end{array}$ \\
\hline $\begin{array}{l}\text { Diphyllobothrium latum (Linnaeus 1758) } \\
\text { (Plerocercoid) }\end{array}$ & $\begin{array}{l}\text { Canada (Margolis \& Arthur 1979), } \\
\text { Argentina (Szidat \& Soria 1952, Revenga 1993), } \\
\text { Chile (Torres et al. 1989), } \\
\text { Norway (Halvorsen \& Wissler 1973). }\end{array}$ \\
\hline $\begin{array}{l}\text { Diphyllobothrium cordiceps (Leidy 1872) } \\
\text { (Plerocercoid) }\end{array}$ & $\begin{array}{l}\text { Canada (Margolis \& Arthur 1979), } \\
\text { North America (Hoffman 1967). }\end{array}$ \\
\hline Eubothrium crassum (Bloch 1779) & $\begin{array}{l}\text { Canada (Margolis \& Arthur 1979), } \\
\text { UK and Ireland (Ingham \& Arme 1973, Kennedy 1974, } \\
\text { Kennedy et al. 1991), } \\
\text { Germany (Otto \& Körting 1973, Engelhardt \& Mirle 1993), } \\
\text { Denmark (Buchmann et al. 1995). }\end{array}$ \\
\hline Eubothrium salvelini (Schrank 1790) & $\begin{array}{l}\text { USSR (Pugachev 1984), } \\
\text { Canada (Mudry \& Anderson 1977, } \\
\quad \text { Margolis \& Arthur 1979), } \\
\text { Germany (Otto \& Körting 1973), } \\
\text { USA (Muzzall 1989, 1993). }\end{array}$ \\
\hline Ichthyotaenia sp. (plerocercoid) & Italy (Joyeux \& Baer 1933). \\
\hline
\end{tabular}


Table 1 - continued

\begin{tabular}{|c|c|}
\hline Species name & Country/region, and author (year) \\
\hline $\begin{array}{l}\text { Ligula intestinalis (Linnaeus 1758) } \\
\text { (plerocercoid) }\end{array}$ & $\begin{array}{l}\text { New Zealand (Weekes \& Penlington 1986), } \\
\text { North America (Hoffman 1967). }\end{array}$ \\
\hline $\begin{array}{l}\text { Paradilepis simoni (Rausch 1949) } \\
\quad \text { (metacestode) }\end{array}$ & Canada (Lei-Ching 1982). \\
\hline Phyllobothrium sp. & North America (Hoffman 1967). \\
\hline Proteocephalus sp. & $\begin{array}{l}\text { Canada (Margolis \& Arthur 1979), } \\
\text { Ireland (Ingham \& Arme 1973), } \\
\text { North America (Hoffman 1967, Muzzall 1993), } \\
\text { Denmark (Buchmann et al. 1995). }\end{array}$ \\
\hline Proteocephalus neglectus (La Rue 1911) & $\begin{array}{l}\text { CS (Hanzelova \& Spakulova 1992), } \\
\text { Germany (Priemer 1980, Rosengarten 1985, Reimer 1985, } \\
\quad \text { Engelhardt \& Mirle 1993, Engelhardt et al. 1988), } \\
\text { Italy (Ghittino 1987), } \\
\text { Denmark (Hanzelova \& Scholz 1992). }\end{array}$ \\
\hline Proteocephalus parallacticus (MacLulich 1943) & Ireland (Arme \& Ingham 1972, Kennedy 1974). \\
\hline Proteocephalus percae (Müller 1780) & $\begin{array}{l}\text { UK (Kennedy 1974), } \\
\text { Denmark (From \& Hørlyck 1981, probably P. neglectus, } \\
\text { see Hanzelova \& Scholz 1992). }\end{array}$ \\
\hline Proteocephalus salmonidicola (Alexander 1951) & $\begin{array}{l}\text { Canada (Margolis \& Arthur 1979), } \\
\text { USA (Alexander 1951, Jones \& Hammond 1960), } \\
\text { North America (Hoffman 1967). }\end{array}$ \\
\hline Proteocephalus longicollis (Zeder 1800) & Germany (Reichenbach-Klinke 1954). \\
\hline Proteocephalus exiguus (La Rue 1911) & $\begin{array}{l}\text { Germany (Priemer 1987), } \\
\text { USSR (Konovalov } 1971 \text { cited by Pugachev 1984) } \\
\text { (Note: according to Scholz \& Hanzelova (1994) P. fallax } \\
\text { is a synonym of this species). }\end{array}$ \\
\hline Proteocephalus tumidocollus (Wagner 1953) & $\begin{array}{l}\text { North America (Hoffman 1967), } \\
\text { USA (Wagner 1953, Mamer 1978, Cox \& Hendrickson } \\
\text { 1991) (Note: according to Hanzelova \& Scholz (1993) } \\
\text { this North American species should be considered a } \\
\text { synonym of P. neglectus ). }\end{array}$ \\
\hline $\begin{array}{l}\text { Proteocephalus ambloplitis (Leidy 1887) } \\
\text { Benedict 1900) (Larva) }\end{array}$ & North America (Hoffman 1967). \\
\hline $\begin{array}{l}\text { Proteocephalus pinguis (La Rue 1911) } \\
\quad \text { (immature) }\end{array}$ & North America (Hoffman 1967). \\
\hline Schistocephalus sp. (plerocercoid) & $\begin{array}{l}\text { Canada (Margolis \& Arthur 1979), } \\
\text { North America (Hoffman 1967). }\end{array}$ \\
\hline Tetrarhynchus sp. & North America (Hoffman 1967). \\
\hline Triaenophorus sp. (plerocercoid) & Denmark (Rasmussen \& Bregnballe 1962). \\
\hline Triaenophorus nodulosus (Pallas 1760) & $\begin{array}{l}\text { USSR (Pavlovskii 1964), } \\
\text { Romania (Georgescu et al. 1981), } \\
\text { Germany (Engelhardt et al. 1988), } \\
\text { Denmark (Buchmann et al. 1995). }\end{array}$ \\
\hline
\end{tabular}

(continued) 
Table 1 - continued

Species name

Triaenophorus crassus (Forel 1868)

\section{Nematoda}

Anisakis sp. (larva)

Ascarophis skrjabini (Layman 1933)

Camallanus lacustris (Zoega 1776)

Camallanus sp.

Capillaria salvelini (Polyanski 1952)

Contracaecum sp. (larva)

Contracaecum osculatum

(Rudolphi 1802) (larva)

Contracaecum spiculigerum

(Rudolphi 1809) (larva)

Cucullanus (= Bulbodacnitis) ampullastoma (Maggenti 1971)

Cucullanus truttae (Fabricius 1794) (= C. globosus, C. occidentalis, Truttaedacnitis truttae, Dacnitis truttae, Bulbodacnitis globosa, Bulbodacnitis occidentalis, Bulbodacnitis truttae)

Cystidicola sp.

Cystidicola cristivomeri (White 1941)

Cystidicola stigmatura (Leidy 1886) Skinker, 1931

Cystidicola farionis (Fischer 1778)

Cystidicoloides tenuissima (Zeder 1800)

(= Sterliadachona tenuissima,

S. pedispicula, see De \& Moravec 1979)
Country/region, and author (year)

Canada (Rosen \& Dick 1984),

USSR (Bauer \& Solomatova 1984).

UK (Kennedy 1974, Wootten \& Smith 1975),

Denmark (Christensen \& From 1978),

North America (Hoffman 1967),

USSR (Pugachev 1984 and Konovalov 1971 cited by Pugachev 1984).

USSR (Pavlovskii 1964).

Ireland (Kane 1966, Kennedy 1974),

UK (McGuigan \& Sommerville 1985).

Chile (Torres et al. 1991).

Yugoslavia (Zitnan \& Cankovic 1970).

Canada (Dick et al. 1987),

Chile (Torres et al. 1991).

Finland (Fagerholm 1982).

North America (Hoffman 1967).

USA (Maggenti 1971).

USA (Jones \& Hammond 1960),

North America (Hoffman 1967),

USSR (Pugachev 1984),

Canada (Mudry \& Anderson 1977, Margolis \& Arthur 1979).

Canada (Margolis \& Arthur 1979).

Canada (Black \& Lankester 1980).

Canada (Mudry \& Anderson 1977),

North America (Hoffman 1967).

Ireland (Kane 1966, Kennedy 1974),

USSR (Pavlovskii 1964, Pugachev 1984),

Canada (Margolis \& Arthur 1979, Black \& Lankester 1980), CS (Moravec 1971),

Germany (Otto \& Körting 1973),

USA (Muzzall 1989, 1993).

Canada (Margolis \& Arthur 1979),

CS (Moravec 1971, De \& Moravec 1979),

Bulgaria (Kakacheva-Avramova \& Menkova 1979),

Yugoslavia (Zitnan \& Cankovic 1970, Kazic 1978,

Bristol et al. 1984),

USSR (Konovalov 1971 cited by Pugachev 1984), 
Table 1 - continued

\begin{tabular}{|c|c|}
\hline Species name & Country/region, and author (year) \\
\hline & $\begin{array}{l}\text { Yugoslavia (Kazic 1978), } \\
\text { USA (Maggenti 1973), } \\
\text { Poland (Hoffman 1967). }\end{array}$ \\
\hline Cystidicoloides hardwoodi (Chandler 1931) & North America (Hoffman 1967). \\
\hline Eustrongylides sp. (larva) & $\begin{array}{l}\text { New Zealand (Blair 1984), } \\
\text { Canada (Margolis \& Arthur 1979), } \\
\text { North America (Hoffman 1967), } \\
\text { USA (Kaeding 1981), } \\
\text { Australia (Beumer et al. 1983). }\end{array}$ \\
\hline $\begin{array}{r}\text { Eustrongylides mergorum } \\
\text { (Rudolphi 1809) (larva) }\end{array}$ & Finland (Fagerholm 1982). \\
\hline Goezia ascaroides (Goeze 1782) & USSR (Pavlovskii 1964). \\
\hline Hepaticola bakeri (Mueller et Van Cleave 1932) & North America (Hoffman 1967). \\
\hline Hysterothylacium sp. (larva) & $\begin{array}{l}\text { New Zealand (Blair 1984), } \\
\text { Denmark (Christensen \& From 1978). }\end{array}$ \\
\hline Hysterothylacium aduncum (Rudolphi 1802) & $\begin{array}{l}\text { Finland (Fagerholm 1982), } \\
\text { Bulgaria (Kakacheva-Avramova \& Menkova 1982), } \\
\text { New Zealand (Blair 1984). }\end{array}$ \\
\hline Hysterothylacium gadi (Müller 1776) & Germany (Reimer 1985). \\
\hline Metabronema salvelini (Fujita 1922) & North America (Hoffman 1967). \\
\hline $\begin{array}{l}\text { Philonema oncorhynchi } \\
\text { (Kuitunen-Ekbaum 1933) }\end{array}$ & $\begin{array}{l}\text { USSR (Pavlovskii 1964, Pugachev 1984), } \\
\text { Canada (Margolis \& Arthur 1979), } \\
\text { North America (Hoffman 1967). }\end{array}$ \\
\hline $\begin{array}{l}\text { Philonema agubernaculum } \\
\text { (Simon et Simon 1936) }\end{array}$ & $\begin{array}{l}\text { Canada (Margolis \& Arthur 1979), } \\
\text { North America (Hoffman 1967). }\end{array}$ \\
\hline Philometra sp. & North America (Hoffman 1967). \\
\hline Pseudocapillaria salvelini & UK (Kennedy et al. 1991). \\
\hline Raphidascaris acus (Bloch 1779) & $\begin{array}{l}\text { CS (Moravec 1971), } \\
\text { Yugoslavia (Kazic 1978), } \\
\text { Spain (Torres \& Alvarez-Pellitero 1988). }\end{array}$ \\
\hline Rhabdochona sp. & USA (Wier et al. 1983). \\
\hline Rhabdocona denudata (Dujardin 1845) & $\begin{array}{l}\text { USSR (Pavlovskii 1964), } \\
\text { CS (Moravec 1971). }\end{array}$ \\
\hline Rhabdocona cascadilla (Wigdor 1918) & $\begin{array}{l}\text { Canada (Margolis \& Arthur 1979), } \\
\text { North America (Hoffman 1967). }\end{array}$ \\
\hline Rhabdocona milleri (Choquette 1951) & $\begin{array}{l}\text { Canada (Mudry \& Anderson } 1977, \\
\text { Margolis \& Arthur 1979). }\end{array}$ \\
\hline Rhabdochona hellichi (Sramek 1901) & Bulgaria (Kakacheva-Avramova \& Menkova 1979). \\
\hline Rhabdochona oncorhynchi (Moravec 1981) & Japan (Moravec et al. 1981). \\
\hline
\end{tabular}

(continued) 
Table 1 - continued

\begin{tabular}{|c|c|}
\hline Species name & Country/region, and author (year) \\
\hline $\begin{array}{l}\text { Skrjabinocapillaria bakeri } \\
\quad \text { (Mueller et Van Cleave 1932) }\end{array}$ & Canada (Margolis \& Arthur 1979). \\
\hline Spinitectus sp. & USA (Muzzall 1989). \\
\hline Spinitectus gracilis (Ward et Magath 1917) & North America (Hoffman 1967). \\
\hline $\begin{array}{l}\text { Spinitectus gordoni } \\
\text { (Cordero-del-Campillo 1976) }\end{array}$ & Spain (Cordero-Del-Campillo \& Alvarez-Pellitero 1976). \\
\hline \multicolumn{2}{|l|}{ Acanthocephala } \\
\hline Acanthocephalus anguillae (Müller 1780) & $\begin{array}{l}\text { USSR (Pavlovskii 1964), } \\
\text { UK (Bates \& Kennedy 1990). }\end{array}$ \\
\hline Acanthocephalus lucii (Müller 1776) & $\begin{array}{l}\text { UK and Ireland (Kane 1966, Kennedy 1974), } \\
\text { Yugoslavia (Bristol et al. 1984). }\end{array}$ \\
\hline Acanthocephalus lucidus (Van Cleave 1925) & Japan (Nagasawa \& Egusa 1981). \\
\hline Acanthocephalus dirus (Van Cleave 1931) & $\begin{array}{l}\text { North America (Hoffman 1967), } \\
\text { USA (Muzzall 1984, 1993). }\end{array}$ \\
\hline $\begin{array}{l}\text { Acanthocephalus echigoensis } \\
\text { (Fujita 1920) (= A. acerbus) }\end{array}$ & North America (Hoffman 1967). \\
\hline $\begin{array}{l}\text { Acanthocephalus opsariichthydis } \\
\text { (Yamaguti 1935) }\end{array}$ & Japan (Nakajima \& Egusa 1975). \\
\hline Corynosoma villosum (Van Cleave 1953) & USSR (Pugachev 1984). \\
\hline Echinorhynchus sp. & $\begin{array}{l}\text { Peru (Conroy 1981), } \\
\text { USSR (Konovalov } 1971 \text { cited by Pugachev 1984). }\end{array}$ \\
\hline $\begin{array}{l}\text { Echinorhynchus truttae (Schrank 1788) } \\
\quad(=\text { Metechinorhynchus truttae) }\end{array}$ & $\begin{array}{l}\text { UK and Ireland (Chubb et al. 1964, Kane 1966, } \\
\text { Kennedy 1974), } \\
\text { Germany (Reichenbach-Klinke 1954, } \\
\text { Taraschewski et al. 1990), } \\
\text { Italy (Bertocchi \& Francalanci 1963, Ghittino 1979), } \\
\text { USSR (Pavlovskii 1964), Bulgaria (Kakacheva-Avrmova } \\
\text { \& Menkova 1979, 1982), Yugoslavia (Zitnan \& } \\
\text { Cankovic 1970). }\end{array}$ \\
\hline Echinorhynchus cotti (Yamaguti 1939) & Japan (Nagasawa \& Egusa 1981). \\
\hline Echinorhynchus gadi (Müller 1776) & Germany (Reimer 1985). \\
\hline $\begin{array}{l}\text { Echinorhynchus salmonis (Müller 1784) } \\
\quad \text { (= Metechinorhynchus salmonis) }\end{array}$ & $\begin{array}{l}\text { North America (Hoffman 1967), } \\
\text { USA (Muzzall 1989, 1993), } \\
\text { USSR (Pavlovskii 1964, Pugachev 1984), } \\
\text { Canada (Margolis \& Arthur 1979), } \\
\text { Yugoslavia (Zitnan \& Cankovic 1970). }\end{array}$ \\
\hline $\begin{array}{l}\text { Echinorhynchus leydyi (Van Cleave 1924) } \\
\text { (= Metechinorhynchus leidyi) }\end{array}$ & $\begin{array}{l}\text { North America (Hoffman 1967), } \\
\text { Canada (Margolis \& Arthur 1979). }\end{array}$ \\
\hline $\begin{array}{l}\text { Echinorhynchus lateralis (Leydi 1851) } \\
\text { (= Metechinorhynchus lateralis) }\end{array}$ & Canada (Margolis \& Arthur 1979). \\
\hline
\end{tabular}


Table 1 - continued

\begin{tabular}{|c|c|}
\hline Species name & Country/region, and author (year) \\
\hline Neoechinorhynchus rutili (Müller 1780) & $\begin{array}{l}\text { UK and Ireland (Kane 1966, Kennedy 1974, Lassiere \& } \\
\text { Crompton 1988, Kennedy et al. 1991), } \\
\text { Canada (Margolis \& Arthur 1979), } \\
\text { North America (Hoffman 1967), } \\
\text { USA (Mamer 1978), } \\
\text { Yugoslavia (Bristol et al. 1984), } \\
\text { Germany (Taraschewski et al. 1990). }\end{array}$ \\
\hline Neoechinorhynchus crassus (Van Cleave 1919) & USSR (Pavlovskii 1964). \\
\hline Neoechinorhynchus salmonis (Ching 1984) & Canada (Lei Ching 1984). \\
\hline Paralongicollum nemacheili (Amin 1991) & USSR (Amin et al. 1991). \\
\hline Pomphorhynchus laevis (Müller 1776) & $\begin{array}{l}\text { UK (Kennedy 1974, Kennedy et al. 1978, Bates \& } \\
\text { Kennedy 1991), } \\
\text { Israel (Paperna \& Lahav 1971), } \\
\text { Ireland (Kane 1966, Kennedy 1974), } \\
\text { Yugoslavia (Zitnan \& Cankovic 1970). }\end{array}$ \\
\hline Pomphorhynchus bulbocolli (Van Cleave 1919) & $\begin{array}{l}\text { Canada (Margolis \& Arthur 1979), } \\
\text { USA (Jones \& Hammond 1960, Muzzall 1984), } \\
\text { North America (Hoffman 1967). }\end{array}$ \\
\hline Pomphorhynchus patagoninus (Trejo 1992) & Argentina (Trejo 1992). \\
\hline $\begin{array}{l}\text { Pseudorhadinorhynchus samegaiensis } \\
\text { (Nakajima 1975) }\end{array}$ & Japan (Nakajima \& Egusa 1975). \\
\hline Rhadinorhynchus sp. & North America (Hoffman 1967). \\
\hline Crustacea & \\
\hline Argulus foliaceus (Linnaeus 1758) & $\begin{array}{l}\text { UK and Ireland (Kane 1966, Kennedy 1974, Buchmann et } \\
\text { al. 1995). }\end{array}$ \\
\hline Argulus pugettensis (Dana 1852) & $\begin{array}{l}\text { Canada (Margolis \& Arthur 1979), } \\
\text { North America (Hoffman 1967). }\end{array}$ \\
\hline Caligus sp. & $\begin{array}{l}\text { Denmark (Christensen 1980), } \\
\text { Sweden (Lundborg \& Ljungberg 1977) }\end{array}$ \\
\hline Caligus clemensi (Parker et Margolis 1964) & Canada (Margolis \& Arthur 1979). \\
\hline Caligus elongatus (Nordmann 1832) & $\begin{array}{l}\text { Canada (Margolis \& Arthur 1979), } \\
\text { Denmark (Buchmann et al. 1995). }\end{array}$ \\
\hline Caligus lacustris (Steenstrup et Lütken 1861) & Poland (Reimer 1985). \\
\hline Caligus orientalis (Gussev) & Japan (Urawa \& Kato 1991). \\
\hline Ergasilus nerkae (Roberts 1963) & $\begin{array}{l}\text { Canada (Mudry \& Anderson 1977, Margolis \& } \\
\text { Arthur 1979). }\end{array}$ \\
\hline Ergasilus caeruleus (Wilson 1911) & North America (Hoffman 1967). \\
\hline Ergasilus sieboldi (Nordmann 1832) & Poland (Hoffman 1967). \\
\hline Lepeophtheirus salmonis (Krøyer 1873) & $\begin{array}{l}\text { Canada (Margolis \& Arthur 1979), } \\
\text { Japan (Nagasawa \& Sakamoto 1993), } \\
\text { Denmark (Buchmann et 1995). }\end{array}$ \\
\hline
\end{tabular}

(continued)

Acta vet. scand. vol. 36 no. 3 - 1995 
Table 1 - continued

\begin{tabular}{|c|c|}
\hline Species name & Country/region, and author (year) \\
\hline Lernaea cyprinacea (Linnaeus 1758) & North America (Hoffman 1967). \\
\hline Lernaeopoda bicauliculata (Wilson 1908) & North America (Hoffman 1967). \\
\hline $\begin{array}{l}\text { Salmincola californiensis } \\
\text { (Dana 1852) Wilson } 1915\end{array}$ & $\begin{array}{l}\text { Canada (Margolis \& Arthur 1979), } \\
\text { USSR (Pugachev 1984). }\end{array}$ \\
\hline Salmincola edwardsii (Olsson 1869) & $\begin{array}{l}\text { Canada (Margolis \& Arthur 1979), } \\
\text { North America (Hoffman 1967). }\end{array}$ \\
\hline Salmincola beani (Wilson 1908) & North America (Hoffman 1967). \\
\hline Salmincola carpenteri (Packard 1874) & North America (Hoffman 1967). \\
\hline \multicolumn{2}{|l|}{ Mollusca } \\
\hline Glochidia of Hyridella sp. & New Zealand (Blair 1984). \\
\hline Glochidia of Margaritana sp. & North America (Hoffman 1967). \\
\hline Pisidium sp. & North America (Hoffman 1967). \\
\hline Pisidium (adult) & North America (Hoffman 1967). \\
\hline Glochicia of Unionidae sp. & Canada (Margolis \& Arthur 1979). \\
\hline Glochidia & Colombia (Conroy 1981), UK (Kennedy 1974). \\
\hline \multicolumn{2}{|l|}{ Hirudinea } \\
\hline Batracobdella xenoica (Ringuelet 1975) & Colombia (Ringuelet 1975). \\
\hline Illinobdella sp. & $\begin{array}{l}\text { Canada (Margolis \& Arthur 1979), } \\
\text { North America (Hoffman 1967). }\end{array}$ \\
\hline Piscicola milneri (Verril 1871) & Canada (Dies 1990). \\
\hline Piscicola geometra (Linnaeus 1758) & $\begin{array}{l}\text { USSR (Pavlovskii 1964), } \\
\text { Denmark (From 1975). }\end{array}$ \\
\hline Piscicola salmositica (Meyer 1946) & North America (Hoffman 1967). \\
\hline
\end{tabular}

\section{Discussion and conclusions}

The rainbow trout is an easily maintained species in both freshwater and marine aquacultural enterprises. This fish species is readily held in ponds, fish tanks and netcage systems and the propagation of fry is a well established activity. The farming of rainbow trout has therefore expanded considerably during the latest decades and extensive stocking of free waters (natural lakes and marine areas) with fry or fingerlings of this salmonid is common practice throughout large parts of the world. The number of metazoan parasites infecting $\mathrm{On}$ corhynchus mykiss is huge and reflects the cosmopolitan habit of transplanting this species into new habitats and ecosystems all over the world. In addition the susceptibility of this host to various parasitic pathogens is accentuated by the checklist. Thus the present list includes a total of 169 taxonomic entities although some of these may turn out to be synonyms in thorough analyses. Thus Hanzelova \& Scholz $(1992,1993)$ subjecting specimens of Proteocephalus from various sources 
for a morphometric analysis have thrown doubt on the validity of the various species in the genus Proteocephalus. According to Amin (1985) who revised and analysed the acanthocephalan groups the genus Metechinorhynchus is now included in Echinorhynchus and the number of recorded acanthocephalans in the list is reduced accordingly. Likewise the work of Moravec (1971) and De \& Moravec (1979) evaluating several nematode species synonymized many earlier records.

A total of 15 monogenean species have been recovered from Oncorhynchus mykiss. Except for 3 species these belong to the genus Gyrodactylus. Various aspects of this genus parasitizing salmonid hosts were treated by Malmberg (1993). It is a parasite group creating considerable problems in both cultured and feral salmonids but experimental evidence of a possible parasite pathogenicity to the host Oncorhynchus mykiss still lack for some species. Of special Eurasian interest is the effect of $G$. salaris and $G$. derjavini on rainbow trout. Bakke et al. (1991) demonstrated that Oncorhynchus mykiss is able to keep the infection with $G$. salaris at a relatively low level in contrast to the extremely susceptible Atlantic salmon. Likewise Cusack (1986) and Cone \& Cusack (1989) elucidated the relative resistance of the rainbow trout to Gyrodactylus colemanensis. Heavy infections of the same host with $G$. derjavini need treatment in Denmark (Malmberg \& Malmberg 1991, Malmberg 1993). Therefore, future controlled experiments should clarify the susceptibility of the rainbow trout to $G$. derjavini.

A wide selection of digenean trematodes (a total of 37 species) has been found in Oncorhynchus mykiss as adult forms or as metacercarial stages. The best investigated effects of digeneans on the fish host concern the impacts of diplostomid metacercariae on the fish intermediate host. Thus it is well known that eyeflukes elicit parasitic cataract in rainbow trout (Rushton 1937, Sato et al. 1976, Shariff et al. 1980) and affect the growth of the fish (Buchmann \& Uldal 1994). Through the removal of intermediate hosts (pulmonate freshwater snails) or elimination of final hosts (fish eating birds) it is possible to control this helminthosis. Further research on prophylactic measures should be conducted. However, if fish are infected they can be cured. Praziquantel (Droncit) was found to kill metacercariae in infected hosts (Bylund \& Sumari 1981).

The pathogenicity of other digenean metacercariae in rainbow trout has indeed been elucidated. Thus, the negative parasitic impact on this fish host was reported for Cotylurus erraticus by Johnson (1971), for Nanophyetus salmincola by Butler \& Millemann (1971) and for Apatemon gracilis by Tort et al. (1987).

Metacercariae of the genera Clinostomum, Nanophyetus and Echinochasmus recorded in rainbow trout are potentially infective to humans (Williams \& Jones 1994). Thus ingestion of raw or undercooked fish from infected areas should be avoided.

Of the 27 species of cestodes recorded from rainbow trout many are pathogenic to this host. The weight reducing effects of Eubothrium crassum in salmonids were elucidated by Berland (1991). The devastating impact of Triaenophorus plerocercoid infections were stated by Bauer \& Solomatova (1984) and by Engelhardt et al. (1988). The latter authors did also elucidate the pathogenicity of Proteocephalus cestodes. However, these tapeworms have complicated life cycles and management procedures (removal of intermediate copepod hosts) may reduce or eliminate infections in intensive systems. Thus, only fish from 1 of 5 trout farms in Denmark were found infected (at a low level) with cestodes. This infection was probably achieved through 
ingestion of intermediate hosts (copepods) entering the farm with inlet water from a natural lake (Buchmann et al. 1995).

Public health aspects of cestode invasions in rainbow trout mostly concern the Diphyllobothrium latum plerocercoids which have been found in South America (Revenga 1993), Canada (Margolis \& Arthur 1979) and Norway (Halvorsen \& Wissler 1973). However, this and related species potentially infective to humans will be absent from intensive farm systems where infected copepods are eliminated.

The pyloric nematode Cucullanus truttae elicit damage to pyloric caeca in infected Oncorhynchus mykiss (Dunn et al. 1983). Such infections may reduce growth of this host (Hiscox \& Brocksen 1973). However, human health aspects of nematode infections in fish may be of greater concern. Marine fish offals were previously used for fish feeding in freshwater trout ponds. In some cases marine nematode larvae (e.g. Anisakis sp.) were thereby transferred to the trout, which became infected with infective third stage nematode larvae (Wootten \& Smith 1975). Humans eating raw or undercooked trout were in this way exposed to infection with anisakids with possibility of contracting anisakiasis (Smith \& Wootten 1978). The use of pelleted dry feed in trout farming nowadays eliminate the risc of infecting trout with anisakids.

A number of reports have mentioned the occurrence and possible pathogenicity of the acanthocephalan Echinorhynchus truttae in rainbow trout culture (Reichenbach-Klinke 1954, Bertocchi \& Francalanci 1963, Taraschewski et al. 1990). Also the rectum dwelling worm Pomphorhynchus laevis is known to elicit histopathological changes of the intestinal wall (Wanstall et al. 1986). A large number of other spiny headed worms have been found in rainbow trout. The life cycle of these acan- thocephalans are primarily dependent on amphipods or isopods serving as intermediate hosts and the non-chemical control of these parasites should depend on elimination of these crustaceans.

The branchiuran Argulus foliaceus has not been recorded often in trout farms although the rainbow trout appear to be quite susceptible (Buchmann et al. 1995). Thus, heavily infected moribund 4 year old rainbow trouts from a natural lake on the island of Bornholm in the Baltic was examined by the author in 1992. This crustacean is a well known pathogen in other types of fish farms (Bauer et al. 1973). In addition, sea caged Oncorhynchus mykiss are often heavily infected with the parasitic copepods Lepeophtheirus salmonis and Caligus elongatus. These crustaceans are well known pathogens in salmonid culture (Wootten et al. 1982, Nagasawa \& Sakamoto 1993).

Infestations with leeches are of great concern in both feral and cultured fish stocks due to their potential function as vectors for various pathogens. Transmission of flagellates (Trypanosoma, Trypanoplasma, Cryptobia) and sporozoans (Haemogregarina) are known hazards connected with leech feeding (Rohde 1984). An interesting non-chemical control method was mentioned by Kabata (1985). Perch (Perca fluviatilis) introduced into the ponds was found to predate on leeches and seemed to have some effect on the infection pressure. Such biological control methods deserve additional investigations.

The larval form of freshwater molluscs called glochidia parasitize the gills of fish. The glochidium which is a miniature bivalve attaches to a gill filament and starts feeding on the gill tissue which proliferates vigorously. Control is achieved through eradication or removal of molluscs from the ponds. In addition water inlet should be controlled for their content of larvae (Kabata 1985). 


\section{Acknowledgments}

This work was supported by the Danish Agricultural and Veterinary Research Council and is a part of the programme on Disease prevention, genetics and nutrition in rainbow trout production. The authors are indebted to Mr. Per Jørgensen and Mr. Poul Hansen who translated Russian texts.

\section{References}

Alexander CG: A new species of Proteocephalus (Cestoda) from Oregon trout. J. Parasitol. 1951, 37, 160-164.

Amin OM: Classification. In: Crompton, D.W.T., Nickol, B.B. (eds.): Biology of the acanthocephala. Cambridge University Press. 1985, 27-72.

Amin OM, Bauer ON, Sidorov EG: The description of Paralongicollum nemacheili n.gen., n. sp. (Acanthocephala: Pomphorhynchidae) from freshwater fishes in Kazakh SSR. J. Parasitol. 1991, 77, 26-31.

Andersen K: Abnormal growth pattern of Diphyllobothrium dendriticum in rainbow trout. J. Helminthol. 1979, 53, 39-40.

Anonymous: FAO Fisheries Circular 1991 No. 821, Rev. 1. Rome. 423 pp.

Arata N, Luengo M, Segovia P, Luengo J, Garrido V: Parasitism by Diplostomulum in trout (Salmo gairdneri). Bolet. Chil. Parasit. 1977, 32, 89-92.

Arme C, Ingham L: Proteocephalus sp. in rainbow trout, Salmo gairdneri: a new host record for the Palaearctic. Irish Nat. J. 1972, 17, 241-242.

Bakke TA, Bailey RE: Phyllodistomum umblae (Fabricius) (Digenea, Gorgoderidae) from British Columbia salmonids: a description based on light and scanning electron microscopy. Can. J. Zool. 1987, 65, 1703-1712.

Bakke TA, Jansen PA, Kennedy CR: The host specificity of Gyrodactylus salaris Malmberg (Platyhelminthes, Monogenea): Susceptibility of $\mathrm{On}$ corhynchus mykiss (Walbaum) under experimental conditions. J. Fish Biol. 1991, 39, 4557.

Bates RM, Kennedy CR: Interactions between the acanthocephalans Pomphorhynchus laevis and Acanthocephalus anguillae in rainbow trout: testing an exclusion hypothesis. Parasitology 1990, 100, 435-444.

Bauer ON, Solomatova VP: The cestode Triaenophorus crassus (Pallas) (Pseudophyllidea: Triaenophoridae) as a pathogen of cage-reared salmonids. J. Fish Dis. 1984, 7, 501-504.
Bauer ON, Musselius VA, Strelkov Yu A: Diseases of pond fishes. Israel Program for Scientific Translations, Jerusalem 1973.

Berland B: Cestoda (Bendelmark). (Cestodes, Tapeworms). In: Poppe TT (Ed.): Fiskehelse. (Fish Health) John Grieg Forlag 1991.

Bertocchi D, Francalanci G: Grave infestazione da Echinorhynchus truttae Schrank in trote iridee de allevamento (Salmo gairdneri). (Heavy infection with Echinorhynchus truttae Schrank in farmed rainbow trout. Vet. Ital. 1963, 14, 475481.

Betterton C: Studies on the host specificity of the eyefluke Diplostomum spathaceum, in brown and rainbow trout. Parasitology 1974, 69, 11-29.

Beumer JP, Ashburner, LD, Burbury, ME, Jetté E, Latham DJ: A checklist of the parasites of fishes from Australia and its adjacent territories. Technical Communication No. 48 of the Commonwealth Institute of Parasitology, Commonwealth Agricultural Bureaux 1983, pp. 43-44.

Black $G A$, Lankester, $M W$ : Migration and development of swimbladder nematodes, Cystidicola spp. (Habronematoidea), in their definitive hosts. Can. J. Zool. 1980, 58, 1997-2005.

Blair D: Observations on the life-cycle of the strigeoid trematode, Apatemon gracilis (Rudolphi, 1819) Szidat, 1928. J. Helminthol. 1976, 50, 125132.

Blair D: A checklist and bibliography of parasites of New Zealand freshwater fish. Mauri Ora 1984, 11, 5-50.

Bristol JR, Mayberry LF, Huber D, Ehrlich I: Endoparasite fauna of trout in the Plitvice Lakes National Park. Veterinarski Arhiv 1984, 54, 5-11.

Buchmann K: Cestodes of migratory trout (Salmo trutta L.) from the Baltic Sea. Bull. Eur. Ass. Fish Pathol. 1987, 7, 115-117.

Buchmann $K$, Uldal A: Effects of eyefluke infections on growth of rainbow trout (Oncorhynchus mykiss) in a mariculture system. Bull. Eur. Ass. Fish Pathol. 1994, 14, 104-107.

Buchmann K, Uldal A, Lyholt HCK: Parasite infections in Danish trout farms. Acta vet. scand. 1995, 36, 000-000.

Butler JA, Millemann RE: Effect of the "salmon poisoning" trematode Nanophyetus salmincola, on the swimming ability of juvenile salmonid fishes. J. Parasitol. 1971, 57, 860-865.

Bylund $G$, Sumari $O$ : Laboratory tests with Droncit against diplostomiasis in rainbow trout, Salmo gairdneri. J. Fish Dis. 1981, 4, 259-264. 
Christensen NO: Fiskesygdomme. (Fish Diseases). Royal Vet. Agric. University. Kandrup, Copenhagen. 1980, $126 \mathrm{pp}$.

Christensen S, From J: Rundorme og deres bekæmpelse i dambrugsørreder. (Roundworms and their eradication in farmed trout). Ferskvandsfiskeribladet 1978, 8, 94-100.

Chubb JC, Awachie JBE, Kennedy, CR: Evidence for a dynamic equilibrium in the incidence of cestoda and acanthocephala in the intestines of freshwater fish. Nature, London 1964, 203, 986987.

Cone DK, Cusack R: A study of Gyrodactylus colemanensis Mizelle and Kritsky, 1967 and Gyrodactylus salmonis (Yin and Sproston 1948) (Monogenea) parasitizing captive salmonids in Nova Scotia. Can. J. Zool. 1988, 66, 409-415.

Cone DK, Cusack R: Infrapopulation dispersal of Gyrodactylus colemanensis (Monogenea) on fry of Salmo gairdneri. J. Parasitol. 1989, 75, 702706.

Cone DK, Beverley-Burton M, Wiles M, McDonald $T E$ : The taxonomy of Gyrodactylus (Monogenea) parasitizing certain salmonid fishes of North America, with a description of Gyrodactylus nerkae n.sp. Can. J. Zool. 1983, 61, 2587-2597.

Conroy DA: The importance of fish diseases in relation to the development of salmonid culture in South America. Rivista Italiana Di Piscicoltura e Ittiopatologia 1981, 16, 57-68.

Cordero-Del-Campillo M, Alvarez-Pellitero MP: Spinitectus gordoni n.sp. (Nematoda: Spiruroidea) from brown and rainbow trouts in NW Spain. Revista Iberica de Parasitologia 1976, 36, 36-66.

Cox WT, Hendrickson GL: Observations on the life cycle of Proteocephalus tumidocollus (Cestoda: Proteocephalidae) in steelhead trout, Oncorhynchus mykiss. J. Helminth. Soc. Washington 1991, 58, 39-42.

Crane JW, Mizelle, JD: Studies on monogenetic trematodes XXXI. Five new species of Gyrodactylus from California fishes. J. Parasitol. 1967, 53, 270-273.

Cusack R: Development of infections of Gyrodactylus colemanensis Mizelle \& Kritsky, 1967 (Monogenea) and the effect on fry of Salmo gairdneri Richardson. J. Parasitol. 1986, 72, 663-668.

De NC, Moravec F: Some new data on the morphology and development of the nematode Cystidicoloides tenuissima (Zeder, 1800). Folia Parasitol. 1979, 26, 231-238.
Dick TA, Papst MH, Paul, HC: Rainbow trout (Salmo gairdneri) stocking and Contracaecum spp. J. Wildl. Dis. 1987, 23, 242-247.

Dies K: Leech infestations in trout. Can. vet. J. 1990, $31,119$.

Dunn IJ, Russell LR, Adams JR: Cecal histopathology caused by Truttaedacnitis truttae (Nematoda: Cucullanidae) in rainbow trout, Salmo gairdneri. Int. J. Parasitol. 1983, 13, 441-445.

Engelhardt A, Mirle $C$ : On the formation of the cestode fauna of rainbow trout (Oncorhynchus mykiss) in recently-formed standing waters at an open-cast mine. Appl. Parasitol. 1993, 34, 3349.

Engelhardt A, Mirle C, Granitza I, Petermann H: Untersuchungen zum Vorkommen zur Schadwirkung und Bekämpfung von Proteocephalus neglectus bei Regenbogenforellen in der Netzkäfighaltung.(Investigations on the occurrence, pathogenicity and control of Proteocephalus negelctus in rainbow trout in netcages). Monatshefte für Veterinärmedicin 1988, 43, 169-172.

Ergens R: Gyrodactylus bohemicus sp. nov. (Monogenea: Gyrodactylidae) from Oncorhynchus mykiss (Walbaum) and Salvelinus fontinalis (Mitchell) (Clupeiformes: Salmonidae) in Czechoslovakia. Folia Parasitol. 1992, 39, 391-394.

Fagerholm H-P: Parasites of Fish in Finland. VI Nematodes. Acta Acad. Aboens. Ser. B. 1982, 40 (6), 1-128.

Fritzsche S: Reduction of Diplostomum infection of rainbow trout fry (Salmo gairdneri) in the Dobbin fish farm. Zeitschrift für die Binnenfischerei der DDR 1975, 22, 243-246.

From J: Fiskeigler of deres bekæmpelse. (Fish leeches and their control). Note 53. Danish Trout Culture Research Station. Brøns. Denmark. 1975, 5 pp.

From J, Hørlyck V: First recorded occurrence of Proteocephalus percae (Müller, 1780) in Danish farmed trout. Bull. Eur. Ass. Fish Pathol. 1981, 1, 40-41.

Georgescu R, Mihai S, Petica M, Angelescu N, Dascalescu P: Hepaticola petruschewskii and Triaenophorus nodulosus in fish from nursery ponds and natural waters. Bul. Cercet. Piscic. 1981, 3, 123-130.

Ghittino P: Principal problems in parasitology in Italian fish culture. Parasitologia 1979, 21, 27-33.

Ghittino C: Some cases of proteocephalosis in farmed rainbow trout. Rivista Italiana Piscicoltura e Ittzipatologia 1987, 22, 21-25. 
Gussev AV: Parasitic monogeneans. In Bauer, O.N. (Ed.): Key to parasites of freshwater fishes of the USSR. Vol. 2. Academy of Sciences, Zoological Institute, Leningrad, USSR 1985.

Halvorsen $O$, Wissler $K$ : Studies of the helminth fauna of Norway XXVIII: an experimental study of the ability of Diphyllobothrium latum (L.), $D$. dendriticum (Nitzsch) and D. ditremum (Creplin) (Cestoda, Pseudophyllidea) to infect paratenic hosts. Norw. J. Zool. 1973, 21, 201210.

Hanzelová V, Scholz T: Redescription of Proteocephalus neglectus La Rue, 1911 (Cestoda: Proteocephalidae), a trout parasite, including designation of its lectotype. Folia Parasitol. 1992, 39, 317-323.

Hanzelová V, Scholz T: Systematic status of Proteocephalus tumidocollis (Cestoda: Proteocephalidae), a parasite of salmonid fishes in North America. Helminthologia 1993, 30, 157-161.

Hanzelova $V$, Spakulova $M$ : Biometric variability of Proteocephalus neglectus (Cestoda: Proteocephalidae) in two different age groups of rainbow trout from Dobsina water reservoir (East Slovakia). Folia Parasitol. 1992, 39, 307-316.

Hare GM, Frantsi C: Abundance and potential pathology of parasites infecting salmonids in Canadian maritime hatcheries. J. Fish. Res. Board Can. 1974, 31, 1031-1036.

Hermanns W, Körting W: The histopathology of Cyathocephalus truncatus infection in rainbow trout. Deutsche Tierärztl. Wochenschr. 1986, 94, 71-72.

Hiscox JI, Brocksen RW: Effects of a parasitic gut nematode on consumption and growth in juvenile trout (Salmo gairdneri). J. Fish. Res. Board Canada 1973, 30, 443-450

Hoffman GL: Parasites of North American freshwater fishes. University of California Press. Berkeley and Los Angeles. 1967, 486 pp.

Höglund J: Ultrastructural observations and radiometric assay on cercarial penetration and migration of the digenean Diplostomum spathaceum in the rainbow trout Oncorhynchus mykiss. Parasit. Res. 1991, 77, 283-289.

Ingham L, Arme C: Intestinal helminths in rainbow trout, Salmo gairdneri (Richardson): absence of effect on nutrient absorption and fish growth. J. Fish Biol. 1973, 5, 309-313.

Johnson KA: The migration of Cotylurus erraticus cercariae (Trematoda: Strigeidae) in rainbow trout (Salmo gairdneri) and their effects on the host. J. Parasitol. 1971, 57, 244-251.
Jones KL, Hammond DM: A study of the parasites from rainbow trout of a commercial fish farm in Cache Valley, Utah. Proc. Utah Acad. Sci. 1960, 37, 157-158.

Joyeux C, Baer JG: Sur le cycle evolutif d'un Tenia de serpent. Comptes Rendue des Seances de l'Academie des Sciences 1933, 1906, 1838-1839.

Kabata Z: Parasites and diseases of fish cultured in the tropics. Taylor \& Francis, London and Philadelphia, 1985.

Kaeding LR: Observations on Eustrongylides sp. infection of brown and rainbow trout in the Firehole River, Yellowstone National Park. Proc. Helminthol. Soc. Wash. 1981, 48, 98-101.

Kakacheva-Avramova D, Menkova I: Helminths of Salmonidae. Veterinarna Sbirka 1979, 77, 15-17.

Kakacheva-Avramova D, Menkova I: The helminths of trout (Salmonidae) in freshwater bodies. Veterinarnomeditsinski Nauki 1982, 19, 78-84.

Kane MB: Parasites of Irish Fishes. Scient. Proc. R. Dubl. Soc. 1966, B1, 205-220.

Kazic D: Endohelminths of Salmonida from the artificial lake Piva, Montenegro, Yugoslavia. Verhandlungen Internationale Vereinigung für Theoretische und Angewandte Limnologie 1978, 20, 2154-2158.

Kendall RL: Taxonomic changes in North American trout names. The progressive fish-culturist 1988 , 50, 189.

Kennedy CR: A checklist of British and Irish freshwater fish parasites with notes on their distribution. J. Fish Biol. 1974, 6, 613-644.

Kennedy CR, Broughton PF, Hine PM: The status of brown and rainbow trout, Salmo trutta and $S$. gairdneri as hosts of the acanthocephalan, Pomphorhynhus laevis. J. Fish Biol. 1978, 13, 265-275.

Kennedy CR, Hartvigsen $R$, Halvorsen $O$ : The importance of fish stocking in the dissemination of parasites throughout a group of reservoirs. J. Fish Biol. 1991, 38, 541-552.

Lassiere $O$, Crompton DWT: Evidence for post-cyclic transmission in the life-history of Neoechinorhynchus rutilii (Acanthocephala). Parasitology 1988, 97, 339-343.

Lei Ching H: Report of the metacestode of Paradilepis simoni Rausch, 1949 Cyclophyllidea: Dilepidae) from fish in British Columbia. Can. J. Zool. 1982, 60, 184-186.

Lei Ching H: Description of Neoechinorhynchus salmonis sp.n. (Acanthocephala: Neoechinorhynchidae) from freshwater fishes of British Columbia. J. Parasitol. 1984, 70, 286-291. 
Lei Ching H: Occurrence of the eyefluke, Diplostomum baeri bucculentum Dubois et Rausch, 1948, in salmonid fishes of northern British Columbia. Can. J. Zool. 1985, 63, 396-399.

Lom J, Dykova I: Protozoan parasites of fishes. Developments in aquaculture and fisheries science, Elsevier. 1992, 26, 1-315.

Lucky Z: Fund der Art Gyrodactylus salaris Malmberg, 1956 auf der Haut der Regenbogenforelle (Trutta gairdneri irideus Gibbons, 1855). Sb. Vys. Sk. Zemed. Brne, Rada B: Spis. Vet. 1963, 11, 127-130.

Lundborg LE, Ljungberg $O$ : Infection with Caligus sp. in salmon and rainbow trout in netcages. Nord.Vet.-Med. 1977, 29 (suppl. I), 20-21.

Lux E: Infestation of salmonid fish with Gyrodactylus salaris, a diagnostic and taxonomic problem. Tagung der Fachgruppe "Fischkrankheiten" der DVG, Schiemefeld/Thüringen. Deutsche Veterinärmed. Gesellsch. 1991, 87-98.

Maggenti AR: A review of the family Cucullanidae Cobbold, 1864 and the genus Bulbodacnitis Lane, 1916 with a description of Bulbodacnitis ampullastoma sp.n. (Nematoda: Cucullanidae) from Salmo gairdneri Richardson. Proc. Helminthol. Soc. Wash. 1971, 38, 80-85.

Maggenti AR: Anthelmintics for nematode parasites of fish: I. Control of Sterliadochona pedispicula in Salmo gairdneri by diethyl 2-chlorovinyl phosphate and 2,2 dichlorvinyl dimethyl phosphate pellets. Proc. Helminthol. Soc. Wash. 1973, 40, 94-97.

Malmberg G: Gyrodactylus infestations on species of Salmo in Danish and Swedish hatcheries. Norw. J. Zool. 1973, 21, 325-326.

Malmberg G: Gyrodactylidae and gyrodactylosis of salmonidae. Bull. Fr. Pêche Piscic. 1993, 328, 5-46.

Malmberg G: Salmonid transports, culturing and Gyrodactylus infections in Scandinavia. In: Parasites of freshwater fishes of North-West Europe. Petrozavodsk. 1989, 88-104.

Malmberg G, Malmberg M: Gyrodactylus in salmon and rainbow trout farms. In: Stenmark A, Malmberg $G$ (eds.): Parasites and diseases in natural waters and aquaculture Nordic countries. Naturhistoriska Riksmuseets Reprocentral, Stockholm 1987.

Malmberg G, Malmberg M: Undersökningar angående Gyrodactylus på laxfisk i fria vatten och odlingar under åren 1951-72 och 1986-maj 1991. (Investigations on Gyrodactylus on salmonids in free water and farms during the years 1951-72 and 1986-91). Information från Sötvattenslaboratoriet 1991, 2, 1-30.

Mamer BE: The parasites of trout in Northwest Washington. J. Parasitol. 1978, 64, 314.

Margolis L, Arthur JR: Synopsis of the parasites of Fishes of Canada. Dept. Fish. Oceans, Bulletin 199. Ottawa 1979.

McGladdery EE, Murphy L, Hicks BD, Wagner SK: The effects of Stephanostomum tenue (Digenea: Acantholpidae) on marine aquaculture of the rainbow trout Salmo gairdneri. In Pathology in Marine Science. Proc. 3rd Int. Coll. Pathol. Marine Aquacult. Gloucester Point, Virginia, USA. 1988, 305-315.

McGuigan JB, Sommerville C: Studies on the effects of cage culture of fish on the parasite fauna in a lowland freshwater loch in the west of Scotland. Z. Parasitenkd. 1985, 71, 673-682.

Mizelle JD, Kritsky, DC: Studies on monogenetic trematodes. XXXIII. New species of Gyrodactylus and a key to North American species. Trans. Amer. microsc. Soc. 1967, 86, 390-401.

Mo TA: Variations of opistohaptoral hard parts of Gyrodactylus salaris Malmberg, 1957 (Monogenea: Gyrodactylidae) on rainbow trout Oncorhynchus mykiss (Walbaum, 1792) in a fish farm, with comments on the spreading of the parasite in south-eastern Norway. Systematic Parasitology 1991, 20, 1-9.

Moody J, Gaten E: The population dynamics of eyeflukes Diplostomum spathaceum and Tylodelphus clavata (Digenea: Diplostomatidae) in rainbow trout and brown trout in Rutland Water: 1974-1978. Hydrobiologia 1982, 88, 207-209.

Moravec F: Nematodes of fishes in Czechoslovakia. Acta Sc. Nat. Brno 1971, 5, 1-49.

Moravec F, Margolis L, Boyce NP: Some nematodes of the genus Rhabdochona (Spirurida) from fishes of Japan. Vestnik Ceskoslovenske Spolecnosti Zooloicke 1981, 45, 277-290.

Mudry DR, Anderson RS: Helminth and arthropod parasites of fishes in the mountain national parks of Canada. J. Fish Biol. 1977, 11, 21-33.

Muzzall PM: Parasites of trout from four lotic localities in Michigan. Proc. Helminthol. Soc. Wash. 1984, 51, 261-266.

Muzzall PM: Endohelminths of salmonids from two localities in eastern Lake Michigan, with emphasis on Echinorhynchus salmonis. Can. J. Zool. 1989, 67, 1604-1607.

Muzzall PM: Parasites of parr and lake age Chinook salmon, Oncorhynchus tshawytscha, from the 
Pere Marquette River and vicinity, Michigan. J. Helmintol. Soc. Wash. 1993, 60, 55-61.

Nagasawa K, Egusa S: Acanthocephalus lucidus Van Cleave (Acanthocephala: Echinorhynchidae) from cultured rainbow trout Salmo gairdneri Richardson. Bull. Jap. Soc. Sci. Fish. 1981, 47, 1153-1156.

Nagasawa K, Egusa S: Echinorhynchus cotti Yamaguti, 1935 (Acanthocephala: Echinorhynchidae) in fish of the Kanita river, with a note on the life cycle. Jap. J. Parasitol. 1981, 30, 45-49.

Nagasawa K, Sakamoto S: Infection of the salmon louse Lepeophtheirus salmonis (Copepoda: Caligadae) on seawater-farmed salmonids in Northern Honshu, Japan. Gyobyo Kenkyu 1993, 28, 143-144.

Nakajima K, Egusa S: Acanthocephalus opsariichthydis Yamaguti, 1935, from cultured rainbow trout, Salmo gairdneri irideus, in Japan. Fish Pathology 1975, 10, 53-57.

Nakajima K, Egusa S: Pseudorhadinorhynchus samegaiensis n.sp. (Acanthocephala), from cultured rainbow trout, Salmo gairdneri, in Japan. Fish Pathology 1975, 10, 58-68.

Ogawa K: A monogenean parasite Gyrodactylus masu sp.n. (Monogena: Gyrodactylidae) of salmonid fish in Japan. Bull. Jap. Soc. Sci. Fish. 1986, 52, 947-950.

Otto F, Körting W: Sektionsbericht zu einen Endoparasitenbefall bei Regenbogenforellen. (Section report from a case of endoparasitism of rainbow trout). Veterinärmedizinische Nachrichten 1973, 2, 103-110.

Paperna I, Lahav M: New records and further data on fish parasites in Israel. Bamidgeh 1971, 23, 43-52.

Pavlovskii EN (ed.): Key to parasites of freshwater fish of the USSR. Israel program for scientific translations, Jerusalem 1964.

Palmieri JR, Heckmann RA, Evans RS: Life cycle and incidence of Diplostomum spathaceum $\mathrm{Ru}$ dolphi (1819) (Trematoda: Diplostomatidae) in Utah. Great Basin Naturalist 1976, 36, 86-96.

Poynton SL, Bennett CE: Parasitic infections and their interactions in wild and cultured brown trout and cultured rainbow trout from the river Itchen, Hampshire. In: Fish and Shellfish Pathology (Ed. Ellis, AE.). Academic Press, London 1985. pp. 353-357.

Priemer J: The life-cycle of the cestode Proteocephalus neglectus from rainbow trout Salmo gairdneri. Ang. Parasitol. 1980, 21, 125-133.

Priemer J: On the life-cycle of Proteocephalus exi- guus (Cestoda) from Salmo gairdneri (Pisces). Helminthologia 1987, 24, 75-85.

Prost M: Fish Monogenea of Poland. IX. Two species of Gyrodactylus from Salmonidae. Acta Parasitol. Polon. 1991, 36, 109-113.

Pugachev ON: Parasites of freshwater fishes of North-east Asia. Zoological Institute, USSR Academy of Sciences 1984, 156 pp.

Rasmussen CJ, Bregnballe F: Parasitære lidelser hos $\emptyset$ rreder. (Parasitic trout diseases). Note No. 22 from Danish Trout Culture Research Station Brøns, Denmark. 1962, 64 pp.

Rawstron RR: Harvest and survival of rainbow trout infected with Sanguinicola davisi Wales. Calif. Fish Game 1971, 57, 253-256.

Rehulka J: Remarks on the occurrence of Gyrodactylus salaris Malmberg, 1957 sensu Ergens, 1961 (Monogenoidea: Gyrodactylidae). Vestnik Ceskoslovenske Spolecnosti Zoologicke 1973, 37, 293-295.

Reichenbach-Klinke $H$ : Rückgratverkrümming bei Fischen nach Acanthocephalen (Kratzer)-Befall. (Deformities of backbone of fishes due to acanthocephalan infection). Z. Parasitenkd. 1954, 16, 253-254.

Reimer LW: Die Rolle der Parasiten bei der Fischaufzucht im Brackwasser der Ostsee. Fischerei-Forschung 1985, 23, 97-98.

Revenga JE: Diphyllobothrium dendriticum and Diphyllobothrium latum in fishes from southern Argentina: association, abundance, distribution, pathological effects, and risk of human infection. J. Parasitol. 1993, 79, 379-383.

Ringuelet $R A$ : A new leech from Colombia parasitic on rainbow trout. Neotropica 1975, 21, 1-4.

Rohde K: Diseases caused by Metazoans: Helminths. In: Kinne $O(\mathrm{Ed})$. Diseases of marine animals. IV, 1. Biologische Anstalt Helgoland. Hamburg. 1984.

Rosen R, Dick TA: Experimental infections of rainbow trout Salmo gairdneri Richardson, with plerocercoids of Triaenophorus crassus Forel. J. Wildl. Dis. 1984, 20, 34-38.

Rosengarten R: Parasitologische Untersuchungen an Regenbogenforellen (Salmo gairdneri Richardson) in einer Forellenteichwirtschaft in Westniedersachsen. (Parasitological investigations on rainbow trout (Salmo gairdneri Richardson) in a trout farm in Westniedersachsen. Dissertation. Fachgebiet Fischkrankheiten und Fischhaltung der Tierärztlichen Hochschule Hannover, Germany 1985. 
Rushton W: Blindness in freshwater fish. Nature. London. 1937, 140, 1014.

Sato T, Hoshina T, Horiuchi M: On worm cataract of rainbow trout in Japan. Bull. Jap. Soc. Sci. Fish. 1976, 42, 249.

Schell SC: The life history of Sanguinicola idahoensis sp.n. (Trematoda: Sanguinicolidae), a blood parasite of steelhead trout, Salmo gairdneri Richardson. J. Parasitol. 1974, 60, 561-566.

Shariff $M$, Richards RH, Sommerville C: The histopathology of acute and chronic infections of rainbow trout Salmo gairdneri Richardson with eye flukes, Diplostomum spp. J. Fish Dis. 1980, 3, 455-465.

Shigin AA: Diplostomum infection of carp. In Problemy parasitologii. Trudy VII Nauchnoi Konferentsii Parasitologov USSR. Part II. Kiev, USSR.Izdatelstvo "Naukova Dumka". 1972, pp. 442-443. (Abstract)

Scholz T, Hanzelová V: Taxonomic study of two Proteocephalus species (Cestoda: Proteocephalidae) parasitizing coregonid fishes: the synonymy of $P$. fallax La Rue, 1911 with $P$. exiguus La Rue, 1911. Systematic Parasitology 1994, 27, 1-12.

Smith GR, Stearly RF: The classification and scientific names of rainbow and cutthroat trouts. Fisheries 1989, 14, 4-10.

Smith JW, Wootten R: Anisakis and anisakiasis. Adv. Parasitol. 1978, 16, 93-163.

Swennen C, Heesen HJ, Höcker AWM: Occurrence and biology of the trematodes Cotylurus (Ichthyocotylurus) erraticus, C. (I.) variegatus and C. (I.) platycephalus (Digenea: Strigeidae) in the Netherlands. Netherlands Journal of Sea Research 1979, 13, 161-191.

Szidat L, Soria MF: Diphyllobothriasis in our country. Preliminary note. Prensa Medica Argentina 1952, 39, 77-78.

Taraschewski H, Mehlhorn H, Raether W: Loperamid, an efficacious drug against fish-pathogenic acanthocephalans. Parasitol. Res. 1990, 76, 619-623.

Tiainen OA: Diplostomum metacercariae (Trematoda, Diplostomatidae) as parasites in the eyes of trout and burbot in Finland. Annels zool. fenn. 1966, 3, 172.

Tojo J, Santamarina MT, Ubeira FM, Estevez J, Sanmartin $M L$ : Anthelmintic activity of benzimidazoles against Gyrodactylus sp. infecting rainbow trout Oncorhynchus mykiss. Dis. aquat. Org. 1992, 12, 185-189.

Torres P, Alvarez-Pellitero MP: Studies on the life- cycle of Raphidascaris acus (Nematoda, Anisakidae): in vitro development of the early stages and experimental infection of macroinvertebrates and Salmo gairdneri. Revista Iberica de Parasitologia 1988, 48, 41-50.

Torres P, Torres J, Garrido O, Thibaut J: Research on Pseudophyllidea (Carus, 1813) in Southern Chile. X. Archivos de Medicina Veterinaria, Chile 1989, 21, 51-57.

Torres P, Cabezas X, Arenas J, Miranda JC, Jara C, Gallardo $C$ : Ecological aspects of nematode parasites of introduced salmonids from Valdivia river basin, Chile. Memorias do instituto Oswaldo Cruz 1991, 86, 115-122.

Tort L, Watson JJ, Priede IG: Changes in in vitro heart performance in rainbow trout, Salmo gairdneri Richardson, infected with Apatemon gracilis (Digenea). J. Fish Biol. 1987, 30, 341-347.

Trejo A: A comparative study of the host parasite relationship of Pomphorhynchus patagonicus (Acanthocephala) in two species of fish from Lake Rosario (Chubut, Argentina). J. Parasitol. 1992, 78, 711-715.

Urawa S, Kato T: Heavy infection of Caligus orientalis (Copepoda: Caligidae) on cage rainbow trout Oncorhynchus mykiss in brackish water. Gyobyo Kenkyu 1991, 26, 161-162.

Uzmann JR, Hayduk SH: Larval Echinochasmus (Trematoda: Echinostomatidae) in rainbow trout, Salmo gairdneri. J. Parasitol. 1964, 50, 586.

Wagner ED: A new species of Proteocephalus Weinland, 1858, (Cestoda), with notes on its life history. Transact. Am. Microscop. Soc. 1953, 72, 364-369.

Wales JH: Two new blood fluke parasites of trout. California Fish and Game. 1958, 44, 125-136.

Wanstall ST, Robotham PWJ, Thomas JS: Pathological changes induced by Pomphorhynchus laevis Muller (Acanthocephala) in the gut of rainbow trout, Salmo gairdneri Richardson. Z. Parasitenkd. 1986, 72, 105-114.

Weekes PJ, Penlington B: First records of Ligula intestinalis (Cestoda) in rainbow trout, Salmo gairdneri, and common bully, Gobiomorphus cotidianus, in New Zealand. J. Fish Biol. 1986, 28, 183-190.

Wells PR, Cone DK: Experimental studies on the effect of Gyrodactylus colemanensis and G. salmonis (Monogenea) on density of mucous cells in the epidermis of fry of Oncorhynchus mykiss. J. Fish Biol. 1990, 37, 599-603.

Wier W, Mayberry LF, Kinzer HG, Turner PR: Para- 
sites of fishes in the Gila river drainage in Southwestern New Mexico. J. Wildl. Dis. 1983, 19, 59-60.

Williams HH, Jones A: Parasitic worms of fish. Taylor \& Francis, London, 1994.

Wilson RK, Foreyt WT: Prevalence of Nanophyetus salmincola, the vector of salmon poisoning disease in steelhead trout (Salmo gairdneri) in Idaho. Proc. Helminthol. Soc. Washington 1985, 52, 136-137.

Wisniewski LW: O rodzajach rodziny Coitocaecidae (Trematoda). Archiwum Towarzystwa Naukowego we Lwowie Section 1933, III 6, 1-13 (Engl. Abstr in Helm. Abstr. 1959.)

Wootten R: Occurrence of the metacercariae of $\mathrm{Co}$ tylurus erraticus (Rudolphi, 1809) Szidat, 1928 (Digenea: Strigeidae) in brown trout Salmo trutta L. and rainbow trout $S$. gairdneri Richardson, 1836, from Hanningfield reservoir, Essex. J. Helminthol. 1973, 47, 389-398.

Wootten R, Smith JW: Observational and experimental studies on the acquisition of Anisakis sp. larvae (Nematoda: Ascaridida) by trout in fresh water. Int. J. Parasitol. 1975, 5, 373-378.

Wootten R, Smith JW, Needham EA: Aspects of the biology of the parasitic copepods Lepeophtheirus salmonis and Caligus elongatus on farmed salmonids, and their treatment. Proceedings of the Royal Society of Edingburg (B) 1982, $81,185-197$.
Zitnan R, Cankovic M: Comparison of the epizootological importance of the parasites of Salmo gairdneri irideus in the two coast areas of Bosna and Herzegovina. Helminthologia (Bratislava). $1970,11,161-166$.

\section{Sammendrag}

Checkliste med flercellede snyltere fra regnbueфrreden Concorhynchus mykiss).

En omfattende litteraturgennemgang er blevet gennemført med henblik på udarbejdelse af en liste over de i litteraturen registrerede flercellede snyltere på regnbueørreden (Oncorhynchus mykiss). Der anføres 169 parasitter i listen, hvoraf nogle sandsynligvis ved fremtidige analyser vil vise sig at være synonymer. Af monogener (haptororm) er fundet 15 arter, af cestoder (bændelorm) er registreret 27 arter, medens der er fundet ikke mindre end 37 arter af digener ikter, 39 nematoder (rundorme), 23 acanthocephaler (kradsere), 17 crustaceer (krebsdyrparasitter), 6 mollusker (bløddyr) samt 5 arter af igler i eller på regnbueørreden. De væsentligste arters patogenitet og betydning gennemgås kort. Desuden anvises enkelte kontrolmetoder.

(Received November 30, 1994; accepted April 29, 1995).

Reprints may be obtained from: K. Buchmann, Department of Veterinary Microbiology, Section of Fish Diseases, Royal Veterinary and Agricultural University, Bülowsvej 13, DK-1870 Frederiksberg C, Denmark. 